\title{
Os estados da pesquisa artística, da instituição à obra de arte
}

\section{Vagner Godói}

Resumo: Este artigo propõe uma reflexão renovada sobre a pesquisa do artista, institucionalizada na universidade e considerada uma das qualidades mais proeminentes da arte contemporânea. O texto aproxima o contexto brasileiro do internacional, de modo a conciliar a pesquisa artística universitária com a ideia de pesquisa artística que é intrínseca à obra de arte.

Palavras-chave: pesquisa artística. teoria de artista. circuitos artísticos. transdisciplinaridade.

\section{The States of Artistic Research, from its Institution to the Work of Art}

Abstract: This paper proposes a renewed reflection about artists' research, academically institutionalized and considered one of the prominent qualities of contemporary art. This text approach a close perspective by both Brazilian and international contexts, in order to conciliate academic artistic research with the idea of artistic research intrinsic to the work of art.

Keywords: artistic research. artists' theory. artistic circuits. transdisciplinarity.

I Pós-doutorando no departamento de História da Universidade Estadual Paulista (Unesp), campus de Franca, e membro colaborador do Centro de Investigação e de Estudos em Belas-Artes da Universidade de Lisboa (CIEBA-FBAUL). Doutor e mestre pelo Programa de Pós-Graduação Interunidades em Estética e História da Arte da Universidade de São Paulo (PGEHA USP). Possui graduação em Design Gráfico pela Unesp, campus de Bauru. Vem estudando a história da Pesquisa em Arte e Design a partir de uma perspectiva pós-estruturalista e dos estudos culturais. Vínculo institucional: Universidade Estadual Paulista, Av. Eufrásia Monteiro Petráglia - Jardim Doutor Antônio Petráglia, Franca - SP, 14409160. ORCID: https://orcid.org/0000-0001-8739-5401. Lattes iD: http://lattes.cnpq.br/0862996734952512. São Paulo, Brasil. 


\section{Multiplicidade de significados da pesquisa do artista na universidade}

Pesquisa em arte (ZAMBONI, 1998) é uma expressão histórica amplamente aceita no Brasil para a pesquisa do artista, que é institucionalizada na universidade como linha de pesquisa ou área de concentração. Elevado à disciplina acadêmica, esse novo campo do conhecimento ganha programas de pós-graduação próprios, recebe auxílios e bolsas de agências de fomento e está organizado em uma associação ${ }^{1}$ coerente que congrega artistas-pesquisadores.

Pesquisa artística, do modo como se quer definida aqui, assume os significados da pesquisa em arte, porém se direciona a uma acepção mais aberta, em diálogo com o contexto internacional, contemplando diferentes instituições e circuitos artísticos, evidenciando, acima de tudo, o projeto poético do artista que se relaciona com o pensamento, o conhecimento, a pesquisa, a teoria, as ciências, a filosofia, os outros campos, os outros saberes.

Institucionalizado na universidade, esse tipo de pesquisa vem ocorrendo de forma pioneira aproximadamente desde a década de 1970, em lugares como Brasil, Reino Unido, Japão e Austrália (ELKINS, 2014; BORG, 2009; SU BAKER et al., 2009). Na sequência da Declaração de Bolonha² no contexto europeu, esse tipo de pesquisa começou a ser desenvolvido em outros países, como Holanda, Portugal, Áustria, Suécia, Suíça etc., sendo motivo de uma nova onda de debates sobre o tema, disparados pela transformação ou incorporação das academias e escolas de arte em universidades, com desdobramentos por outras regiões e ainda com repercussões em outros circuitos artísticos e na obra de artistas (BORGDORFF, 2012; SLAGER, 2015). No Brasil, a denominação pode ser pesquisa artística, pesquisa em arte, poéticas visuais (contemporâneas, interdisciplinares, tecnológicas) ou ainda processos artísticos ou de criação. De modo geral, practice-led ou practice-based research no Reino Unido, künstlerische Forschung na Alemanha, recherche-création no Canadá. Também são adotadas expressões

1 Como desdobramento do estabelecimento da área de Artes, em 1987 foi criada a Associação Nacional dos Pesquisadores em Artes Plásticas (Anpap), contando com cinco comitês, incluindo um próprio para a pesquisa dos artistas, hoje chamado de "Poéticas Artísticas". Ver: Zanini (2008); Peccinini (2017).

2 A Declaração de Bolonha é um acordo firmado em 1999 pela União Europeia que determinou a criação de um Espaço Europeu de Ensino Superior (EEES), a uniformização de titulações e currículos em todas as áreas, para que se pudesse estabelecer a comparação entre países, desenvolver critérios únicos de qualidade e metodologias, e também o sistema de três ciclos formado por graduação, mestrado e doutorado. 
como arte como pesquisa, arte baseada em pesquisa, pesquisa criativa, pesquisa através da arte, pesquisa para a arte, entre outras, dependendo do esquema classificatório realizado por cada autor. Clive Cazeaux (2017) diz que todas as expressões têm em comum a palavra "pesquisa", algo geralmente associado às universidades e aos laboratórios, e que o crescimento do vocabulário é sinal de que há um aumento crescente de interesse na área, embora também sejam reveladas incertezas e ansiedades, sobretudo na dificuldade de saber se a arte pode ser pesquisa ou pode criar pesquisa. O autor prefere a expressão "pesquisa artística" porque faz uma relação com "pesquisa científica" e também porque é utilizada na literatura recente, principalmente por nomes importantes como Henk Slager, Michael Schwab e Henk Borgdorff.

Vários pesquisadores e teóricos tentaram definir os significados da pesquisa artística, motivo de vários debates, livros, conferências e exposições, sobretudo nos últimos anos, fenômeno e linha poética que refletem sobre as instituições da arte e também sobre a obra de arte feita agora. A seguir, objetivando um entendimento renovado sobre o tema, de entrelaçamento entre o contexto internacional e o brasileiro, será feita uma síntese de algumas discussões e categorizações propostas por autores como Christopher Frayling (1993), Sandra Rey (1996), Kathrin Busch (2009), James Elkins (2014), Henk Borgdorff (2012), Arlindo Machado (2016), entre outros, em categorias próprias definidas aqui como os sete estados ${ }^{3} \mathrm{da}$ pesquisa artística: 1) pesquisa do artista na universidade; 2) pesquisa de produção artística; 3 ) pesquisa em arte e tecnologia; 4) pesquisa do artista sobre a própria arte; 5) pesquisa teórica de artista; 6) pesquisa do artista associada a outros campos; e 7) pesquisa do artista em vários circuitos. Os estados são elementares, porém abertos: não ocorrem como oposições, já que são considerados os cruzamentos criativos entre qualidades e frequências, assim como a passagem de um estado a outro, em livre trânsito combinatório.

\section{1) Pesquisa do artista na universidade}

O primeiro estado, aqui chamado de pesquisa do artista na universidade, entra em diálogo com o último item, denominado pesquisa do artista em

3 Utiliza-se aqui a palavra "estado" em um entendimento que se conecta à ideia de "estado de invenção" de Hélio Oiticica (2009, p. 241-242). 
vários circuitos, não como uma contraposição, mas para demarcar que o artista pode cursar uma pós-graduação e fazer pesquisa, pode continuar pesquisando na universidade sendo ao mesmo tempo artista-professor e artista-pesquisador, mantendo uma atividade de publicações de livros e artigos, seminários e palestras, além de poder circular por outros circuitos como museus, galerias de arte, bienais, centros independentes de pesquisa etc. A importância deste estado concentra-se no estabelecimento de um lugar próprio para a pesquisa do artista dentro da universidade e na nomeação de um curso ou linha de pesquisa próprios de pós-graduação stricto sensu, enquanto disciplina de criação artística e formação voltada à pesquisa.

Muito próxima dos significados propostos aqui neste estado, "pesquisa artística como disciplina acadêmica" é uma das nove categorias ${ }^{4}$ criadas por Busch (2009) sobre o tema, falando sobre a criação de um lugar para os mestrados e doutorados em arte e a emergência de uma disciplina própria para a criação artística dentro do meio acadêmico. Ainda que a expressão pesquisa artística seja utilizada de forma geral, ou para falar da atividade de busca do material, da referência ou do assunto para a arte, segundo tanto Holert (2009) quanto Borgdorff (2012) ela serve para diferenciar e conectar os domínios da arte e da academia, cruzamento que é institucionalizado como disciplina acadêmica nas fronteiras entre as práticas artísticas e científicas dentro da universidade.

A busca de regras e regulamentações pode ocorrer em virtude de uma questão institucional e do problema da equiparidade arte-ciência para atender os mecanismos de validação, para que artistas-pesquisadores e programas de pós-graduação em Arte recebam financiamentos de pesquisas e bolsas de estudo. O ímpeto inicial por trás do estabelecimento da pesquisa artística em relação à geração de novos conhecimentos, dentro dos sistemas educacionais superiores, ocorre por uma questão financeira, no sentido que sejam criadas as oportunidades para que a produção artística seja reconhecida como uma nova disciplina pelas agências de fomento. Silvio Zamboni (2005, p. 193), hoje professor aposentado do Instituto de

4 Kathrin Busch faz nove categorizações, também com um entendimento ampliado de pesquisa artística, ajudando a distinguir as diferenças entre pesquisas do artista feitas no meio acadêmico daquelas feitas em outros circuitos e instituições da arte: 1) "arte com pesquisa", 2) "arte sobre pesquisa", 3) "arte como pesquisa", 4) "pesquisa artística como disciplina", 5) "pesquisa artística crítica", 6) "arte como uma forma diferente de conhecimento", 7) "poética do conhecimento"”, 8) "hibridização da arte com a pesquisa" e 9) "zona intermediária". 
Artes da Universidade de Brasília (IdA/UnB), e ex-funcionário da coordenação de Ciências Sociais do Conselho Nacional de Desenvolvimento Científico e Tecnológico (CNPq), relembra a dificuldade da oficialização de toda a área de artes pelo CNPq, ocorrida em 1984, que incluiu não só a pesquisa do artista mas também a pesquisa feita pelos historiadores, teóricos, curadores e educadores das Artes Visuais, além dos pesquisadores das subáreas de Música e Artes Cênicas. A dificuldade se deu, diz ele, pelo fato de as outras áreas científicas terem que compartilhar seus recursos com mais uma nova área, que por consequência arremataria uma fatia das provisões: "Pesquisa é feita com recursos, não só no Brasil como em qualquer lugar do mundo. E a briga entre cientistas, entre áreas, entre laboratórios, entre institutos é ferrenha".

A criação deste lugar institucional específico para a pesquisa do artista no meio acadêmico acontece com os esforços de muitos artistas e pesquisadores, em constante tarefa de definição da área e criação de novas metodologias, de modo que a pesquisa artística seja construída como uma nova forma criativa de conhecimento. A pesquisa artística na universidade é um tipo muito específico de pesquisa, sendo um estado que não empresta, sem contestações, os modelos da pesquisa científica ou próprios de outras áreas, pois se define a partir da tradição da própria arte, de sua história e pelo desenvolvimento muito específico dos projetos poéticos de cada artista que se propõe a pesquisar, criando constantemente novos modelos, de forma mutável, plural e aberta.

\section{2) Pesquisa de produção artística}

Outro estado da pesquisa artística é, na denominação utilizada aqui, o da pesquisa de produção artística, um tipo de pesquisa que reivindica a obra de arte ou criação artística como o próprio resultado da pesquisa, ou ainda, parte dela quando associada a textos acadêmicos, relatórios, artigos, dissertações e teses, ou a outras atividades acadêmicas. A obra de arte, material ou discursiva, é o elemento principal da pesquisa. Dentro da universidade, possui ligação forte com o estado anterior, pois programas de pós-graduação em Arte foram criados para possibilitar a defesa da produção artística, mesmo que essa qualidade não seja preponderante sobre determinada pesquisa ou outra, ou que pesquisas de produção sejam esboçadas em programas de outras áreas. É um dos estados mais comuns e muito discutido no contexto recente europeu porque, caso predomine, privilegia a obra de arte em relação ao texto ou à pesquisa teórica, ou, em muitos momentos, é somente a obra que é defendida. 
Frayling (1993) possui uma denominação específica para essa característica, que ele chama de "pesquisa para a arte e o design" ${ }^{5}$, sendo a pesquisa que objetiva como produto final do conhecimento o próprio artefato, obra de arte, produto ou peça do design, em que o pensamento está incorporado nele, no sentido de comunicação visual, icônica ou imagística. Daí que o objetivo principal não é fazer um relatório verbal sobre a prática artística ou de design, mas apresentar a própria produção. Aqui o autor elabora uma característica que, ainda no limite, é muito difícil de ser aceita nos meios acadêmicos, o resultado de uma pesquisa, publicação, atividades acadêmicas, dissertação ou tese compreendidas pela produção, que prescinde de uma explanação teórico-discursiva, e que se sustenta em uma tradição cognitiva oriunda da própria materialidade artística. Frayling diz que não são oferecidos títulos na universidade para pesquisas em que a "arte fala por si mesma". Nesse caso extremo, o autor diz que "toda a história da arte" seria passível de receber, nestes termos, um título acadêmico de pós-graduação.

No início da pesquisa em arte no Brasil, no primeiro Programa de Pós-graduação em Artes Visuais do país, desenvolvido na Escola de Comunicações e Artes da Universidade de São Paulo (ECA-USP), os artistas Regina Silveira, Carmela Gross e Evandro Carlos Jardim defenderam dissertações e teses muito próximas da ideia de pesquisa de produção artística, com predominância definitiva da obra de arte sobre o texto teórico ou descritivo, procurando deslocar-se de metodologias de outras áreas. Em 1980 Regina Silveira apresenta Anamorfas, resultado da sua pesquisa de mestrado orientada pelo historiador da arte Wolfgang Pfeiffer, composta de um texto descritivo, de álbum com 12 gravuras, e de uma exposição no Museu de Arte Contemporânea da Universidade de São Paulo (MAC USP). Logo, em 1984, a artista inaugura a pesquisa artística na universidade brasileira realizada em um programa próprio para isso, ao defender a tese de doutorado Simulacros. Parte da produção desenvolvida foi exibida na $17^{\mathrm{a}}$ Bienal de São Paulo, em 1983.

A pesquisa de produção artística acontecerá de forma pioneira também no Reino Unido, sendo o primeiro doutorado prático defendido em 1978 pelo artista Andrew Stonyer, com o título de The Development of Kinetic

5 Christopher Frayling cria três categorias para dar conta da pesquisa em arte e em design feita na academia: "pesquisa dentro da arte e do design", "pesquisa através da arte e do design" e "pesquisa para a arte e o design". Essa categorização serviu de referência para várias explorações posteriores sobre os significados da pesquisa no design e recentemente para as discussões renovadas sobre a pesquisa artística. 
Sculpture by the Utilisation of Solar Energy, muito próximo da arte tecnológica. O modelo britânico de pesquisa artística foi criado a partir da década de 1970 nos institutos politécnicos, para dar conta tanto da pesquisa feita nas artes visuais, música, artes cênicas e design, e desse modo foram desenvolvidos mestrados e doutorados em torno da ideia de "pesquisa baseada na prática" (BORG, 2009, p. 87).

Mabe Bethônico, da Universidade Federal de Minas Gerais (UFMG), diz que as produções artísticas para a pesquisa do artista no contexto acadêmico "são parte do processo e resultado do trabalho, de modo indissociável". Outros artistas-pesquisadores também foram questionados por e-mail, no processo de pesquisa que originou este texto, sobre o grau de importância entre produção artística (obras de arte, projetos, ações, publicação de artista, instalação, performance etc.) e produção teórica (artigos, teses, dissertações, comunicações etc.) como resultado da pesquisa artística. Para Milton Machado, da Universidade Federal do Rio de Janeiro (UFRJ), não há diferença entre produção teórica e produção artística, pois "ambas são Produção. Ambas são Trabalho. O que mais importa é fazer com que a diferenciação produza a diferença, que é o que produz o movimento". Hélio Fervenza diz que no Programa de Pós-graduação do qual faz parte, na Universidade Federal do Rio Grande do Sul (UFRGS), "a exposição ou exibição pública da produção artística realizada durante o curso é obrigatória", no caso de defesa de teses e dissertações. Tanto Fervenza quanto Livia Flores, da UFRJ, acreditam que as pesquisas artísticas trabalham com conceitos, reflexões e referências artísticas que surgem ou estão em diálogo com a produção artística do pesquisador. Para Flores, idealmente, tanto produção artística quanto produção teórica "têm a mesma importância" como pesquisa do artista na universidade, "embora sejam pesquisas de natureza diversa”. Essa diferença também é colocada por Milton Sogabe, professor aposentado da Universidade Estadual Paulista (UNESP), para quem a pós-graduação stricto sensu forma um pesquisador e possível orientador de pesquisas tanto teóricas quanto teórico-práticas. Para Raquel Stolf, da Universidade do Estado de Santa Catarina (Udesc), a produção teórica acaba transformando-se, em muitos momentos, ela mesma em produção artística, quando há "uma intersecção e interdependência" entre elas, no momento em que é permitido "pensar/propor a própria tese/dissertação como trabalho/projeto artístico"6.

6 Resposta de alguns artistas-pesquisadores a questões colocadas por e-mail. 
A pesquisa de produção artística é um tipo de pesquisa que fica entre a reflexão teórica e a construção de obras de arte. Dentro do panorama extremamente discursivo das pesquisas em ciências humanas, trata-se de uma aventura justificar-se apenas com produção, perante outras áreas do conhecimento como a filosofia, a história e a sociologia. De fato, houve um momento em que foi necessário defender a produção do artista no meio universitário como uma prática válida de pesquisa. Porém, a prática do artista na universidade brasileira não deveria mais ser defendida ou legitimada, já deveria ser compreendida e aceita. Em uma época marcada por obras de arte que trabalham a discursividade e o texto (BASBAUM, 2007), não faz mais sentido defender um modelo prático sobre o teórico, pois se corre o perigo de elevá-lo à única possibilidade de trabalho da pesquisa artística, fazendo com que sejam esquecidas outras possibilidades de pesquisa, como: aquelas que não objetivam a produção de obras de arte em um sentido objetual ou material; obras de arte que estão no limite com o conhecimento, os processos educativos ou de pesquisa teórica; pesquisas que dão origem a obras completamente constituídas pelo discurso, por textos ou teorias; pesquisas artísticas pensadas de forma híbrida, sem uma preocupação definida com teoria ou prática; e ainda aqueles casos em que a teoria é considerada prática artística. Por isso, o termo utilizado aqui é pesquisa de produção artística e não "pesquisa de prática artística".

\section{3) Pesquisa em arte e tecnologia}

Será utilizada a expressão pesquisa em arte e tecnologia como uma das denominações para um dos estados da pesquisa artística, dentre os sete propostos aqui, com significados muito próximos do estado anterior, da produção artística, mas de um tipo que se predispõe ao técnico e ao tecnológico, à computação e à engenharia, em que descobertas e construções originadas da produção artística estão muito próximas dos centros de pesquisa, do laboratório tecnocientífico, e mesmo das empresas de inovação. Esse estado também pode dar origem a várias denominações de arte, que podem variar de autor, tipo de arte, tecnologia utilizada, época e contexto, como "arte cinética", "intermídia", "arte cibernética", "videoarte" "computação gráfica", "arte de sistemas", "arte eletrônica", "arte robótica" ou "cyborg art", "arte multimídia", "arte virtual”, "arte digital", "net art" ou "web art", "arte interativa", "new media art", "arte tecnológica" etc. Outros autores e artistas podem nomear o terreno específico das artes visuais que se relaciona com a tecnologia como arte tecnológica ou simplesmente "arte e tecnologia", com o propósito de abranger variados tipos de produções artísticas que vêm se desenvolvendo em variados movimentos, teorizações e definições, com uma história consistente que atravessa 
o século 20, inclusive no Brasil, e chega até hoje como um campo bem definido de criação. Às vezes apartada do restante da arte, em uma atitude mais engajada sobre a utilização pela arte dos meios tecnológicos, a arte tecnológica é motivo de inúmeros congressos, festivais e exposições, com um número considerável de artistas-pesquisadores, geralmente em proximidade com a universidade, em centros de pesquisa, programas de pós-graduação e até museus que trabalham nessa interface ${ }^{7}$.

No esquema amplo proposto por Elkins (2014, p. 317-318), baseado em três grandes modelos para a pesquisa artística e seus resultados ${ }^{8}$, existe uma subdivisão da primeira categoria, própria à prática artística e sua exposição em um texto direcionado, em que a "dissertação ou tese é um relatório técnico", no caso dos mestrados e doutorados, mas esta ideia pode ser expandida para qualquer pesquisa artística que se relaciona a tecnologia, documentada em textos acadêmicos. Esse estado pode falar, também, sobre qualquer relação do tipo técnica ou tecnológica, como a investigação sobre técnicas e materiais realizada pelos artistas e designers, por exemplo. Porém, o autor não cita o caso da arte tecnológica, nem exemplos em que o design trabalha sobre inovações tecnológicas de produtos e serviços.

A ideia de uma pesquisa em arte e tecnologia, próxima da ideia de pesquisa de produção artística, não se restringe ao campo da arte, segundo Michael Biggs (2008), para quem os projetos baseados na prática são aqueles que incluem um artefato original como parte da produção, em adição ou, talvez, no lugar de uma dissertação ou tese escrita, algo que é do interesse de vários profissionais que objetivam a criação de técnicas, procedimentos, artefatos e produtos, trabalhando em laboratórios e em institutos de inovação ligados a empresas, como todos os tipos de designers, mas também arquitetos, músicos, projetistas de software, engenheiros, médicos, enfermeiros e de variadas áreas de pesquisa que têm um interesse no conhecimento aplicado em alguma produção, e é de grande importância o conhecimento que é gerado com a produção. Por sua vez, Henk Slager (2015, p. 17) propõe uma arte, não necessariamente tecnológica, feita em laboratórios experimentais de pesquisa artística objetivando a criação

7 Para um princípio de entendimento do tema, ver as contribuições de Douglas Davis (1973), Diana Domingues (1997), Lev Manovich (2001), Edmond Couchot (2003) e Priscila Arantes (2005).

8 James Elkins faz uma categorização extensa sobre os doutorados em Arte, composta de três modelos propositivos: 1) "dissertação ou tese que informa a prática artística", 2) "dissertação ou tese que equivale à obra de arte", e 3) "dissertação ou tese como obra de arte, e vice-versa". 
de novos conhecimentos e experiências, como um espaço especulativo, tanto de discussões quanto de produções.

Em um novo modelo de laboratório para a arte de agora, dentro ou fora da universidade, pode-se vislumbrar um novo entendimento da arte, que não vê as relações entre arte e tecnologia apartadas em terreno próprio, compartimentada em uma única categoria, separada de outros circuitos da arte. A arte tecnológica deve aproveitar sua competência em ficar sempre na fronteira, para que se dissolva em novas conexões com outros campos e circuitos ainda mais diversos, em cruzamentos múltiplos entre conhecimentos, tecnologias, assuntos, materiais e linhas poéticas.

\section{4) Pesquisa do artista sobre a própria arte}

A pesquisa do artista sobre a própria arte é um dos estados fundamentais da pesquisa artística, um empenho metalinguístico em compreender o próprio campo e os fenômenos artísticos, uma reflexão do artista sobre sua própria obra e a de outros artistas. Não foram poucos os autores, pesquisadores e artistas que escreveram sobre as artes visuais através dos tempos ou tomaram obras de arte como referências para construir teorias, conceitos e ideias sobre a arte. No entanto, no limite, toda obra de arte pensa, analisa e reprocessa a arte anterior e a de seu próprio tempo, daí que a pesquisa artística pode debruçar-se e desenvolver-se sobre o pensamento que vem da própria produção artística.

Haroldo de Campos (1992, p. 260) utiliza a ideia de metalinguagem, uma das seis funções da linguagem propostas por Roman Jakobson, para caracterizar o trabalho crítico do poeta: "Em primeiro lugar, eu gostaria de assinalar que esta oposição entre 'poetas doutos' (capazes de reflexão teorética ou 'metalinguística', no sentido que a linguística de hoje dá a este último termo) e 'poetas ingênuos' (da 'inspiração', do 'coração') vem de longe". Nessa mesma linha, Julio Plaza (2003) coloca a universidade como um lugar privilegiado das relações "entre o 'fazer' e o 'saber' artísticos", e evidencia as aproximações e diferenças da arte com as atividades do filósofo e do cientista sobre o conhecimento, até então mais nítidas nesse ambiente. Para o autor, o processo de produção artística dá origem ao próprio modo de fazer da obra de arte, pois "os artistas querem entender como se processa o fazer, este é seu significado. Este querer-saber-do-fazer é ir ao encontro da metalinguagem própria do artista, ou seja, aquela que diz respeito à Poética como processo formativo e operativo da obra de arte" (PLAZA, 2003, p. 46). Um aspecto muito especial que é parte da história e do contexto da pós-graduação em Arte, e que espanta determinados 
pesquisadores de outras áreas, segundo Sogabe (2014, p. 26), é o fato de a própria obra do artista-pesquisador, muitas vezes, ser seu objeto de pesquisa, um trabalho de compreender sua própria obra, fazendo conexões com a arte ou outros campos do conhecimento. Segundo o autor, algumas pesquisas se concentram sobre a obra de arte já produzida, tentando fazer as conexões e classificações necessárias sobre um universo já construído, em um tipo muito comum de pesquisa do artista sobre a própria obra que resulta em um texto retrospectivo de sua trajetória, amparado pela criação de conceitos ou teorizações sobre um corpo de trabalhos. Sandra Rey, da UFRGS, em um texto de 1996 chamado "Da prática à teoria: três instâncias metodológicas sobre a pesquisa em artes visuais" faz um alerta, naquele momento, para a necessidade de consolidação da área da pesquisa artística entre as outras áreas já mais estabelecidas, com a interessante diferenciação entre "pesquisa em arte" e "pesquisa sobre arte". A "pesquisa em arte", prática de estúdio e reflexão teórico-poética motivada pela própria prática, "delimita o campo do artista-pesquisador", ou seja, é a pesquisa do artista na universidade, tal como foi designada por Zamboni, para particularizá-la de outras pesquisas feitas pelos artistas. Avançando sobre essa ideia, Rey (1996, p. 82) destaca, em contraposição, a "pesquisa sobre arte", que é a pesquisa do historiador, do teórico e do crítico de arte.

O estado da pesquisa do artista sobre a própria arte, preocupado em compreender e refletir a arte, estudar a própria produção artística e a de outros artistas, articula-se com todos os outros, pois essa reflexão é essencial para qualquer pesquisa artística. Em alguns momentos, pode acabar sendo confundido com o estado da "pesquisa teórica de artista". A pesquisa do artista sobre a própria arte é tanto teórica e discursiva quanto de produção e serve como um contraponto ao estado da pesquisa artística que está interessado em outros campos do conhecimento.

\section{5) Pesquisa teórica de artista}

O estado da pesquisa teórica de artista fala sobre a inserção do artista em uma arena de debates e reflexões teórico-discursivas, seja na universidade, seja em outros espaços e instituições, determinando uma compreensão da pesquisa a partir da leitura de textos e obras de arte, do desenvolvimento de escritos e teorias de artistas, da criação de conceitos e sistemas conceituais por parte dos artistas. $O$ estado também fala sobre o pensamento e as ideias do artista ganhando uma condição pública, seja em uma oficina 
ou palestra, seja em uma palestra-performance ${ }^{9}$ ou uma oficina considerada como obra de arte. Parece que esse estado tem as mesmas propriedades do estado anterior, se for levado em consideração que toda pesquisa teórica feita pelo artista poderá ocorrer estritamente sobre o domínio da arte, sem entrelaçamento com outros campos do conhecimento, mas isso seria menosprezar a capacidade da arte de criar simultaneamente vários vínculos. A inclusão desse estado tampouco serve como contraposição ao estado da pesquisa de produção artística, visto que para a arte contemporânea a ideia de produção pode ser considerada de forma mais ampla, nos casos em que a produção teórico-discursiva do artista adentra a própria obra ou se torna parte do projeto poético.

Para Anne Cauquelin (2005), teoria da arte significa uma atividade que constrói, transforma ou modela o campo da arte, e a expressão teorias da arte, no plural, serve para situar cada um dos lugares onde ocorre a reflexão sobre a arte. Esses lugares são divididos por ela em dois grandes tipos, o das teorias de fundação, que são os pensamentos filosóficos sobre a arte, tal como iniciado pelos gregos na Antiguidade, e as de acompanhamento, que são tanto as teorias secundárias como a Linguística, a Psicanálise, a Fenomenologia, História etc., quanto as práticas teorizadas. Segundo Cauquelin (2005, p. 129-130), as práticas teorizadas "nascem ao mesmo tempo em que as obras que sustentam" e estão intimamente "ligadas ao objeto que as incita a existir". Nessa categoria estão incluídos a crítica de arte e também os escritos e as teorias de artista. A autora argumenta que o texto do artista, entre a pintura e o pensamento, a imagem e a palavra, a prática e a teoria, assegura "a intermediação entre o não verbal e o verbal, de maneira a juntar os dois", e assim passa a não responder "mais aos cânones das teorias fundadoras", resistindo à interpretação dos críticos, adquirindo um outro estatuto, pois "passa a fazer parte do dispositivo artístico", tomando a forma de um "texto-objeto" (CAUQUELIN, 2005, p. 155-157). Jonathan Dronsfield (2014) explica a sua ideia de "materialidade da teoria" a partir dos desenvolvimentos recentes da pesquisa artística nas academias europeias, e em exemplos da própria produção de arte contemporânea, em artistas como Cerith Wyn Evans, Thomas Hirschhorn, Benoît Maire e Hito Steyerl que, segundo ele, tem feito uso da teoria como material constituinte de suas práticas, utilizando a teoria

9 A palestra-performance é parte da prática de uma geração recente de artistas, tais como Leandro Cardoso Nerefuh, Hito Steyerl, Sarah Pierce, Falke Pisano, Benoît Maire, Nikolaus Gansterer, Xavier Le Roy, Jérôme Bel, Simon Fujiwara, Henrik Olesen, Alexandre Singh, Alicia Herrero etc. 
como se fosse qualquer outro material artístico. São artistas que trabaIham imagem e texto até o limite em que ambos se tornam indiscerníveis. Assim, o autor também defende que doutorados em Arte sejam compostos só de texto, mas um texto de outra qualidade, aquele que é ao mesmo tempo teoria e produção artística. Para ele, o uso performativo da teoria pelos artistas revela a materialidade do texto, concede maior controle para o artista sobre a interpretação dos seus trabalhos, testa as fronteiras do que é entendido como arte e mostra a indistinção entre teoria e prática.

As qualidades do estado da pesquisa teórica de artista podem ser vistas em diversos artistas contemporâneos, inseridos ou não no ambiente universitário, que estão interessados em discorrer teoricamente sobre temas que vêm da sua própria produção artística, mas, sobretudo, de temas urgentes que surgem de um embate da arte com a sociedade, a vida, e outros campos do conhecimento, que publicam textos em revistas ou como livros de artista, que criam escolas temporárias e projetos discursivos como oficinas, aulas e palestras-performance, que defendem teses e dissertações como resultado das pesquisas artísticas ou como obras de arte, que trabalham a materialidade do texto e da teoria, até o momento em que um ambiente teórico e de pesquisa instala-se na obra de arte.

\section{6) Pesquisa do artista associada a outros campos}

A pesquisa do artista associada a outros campos acontece quando o artista começa a se interessar pelos mais variados campos do conhecimento $^{10}$, pertencentes, por exemplo, às ciências humanas e sociais, às ciências da vida, às ciências agrárias, em um interesse que pode se tornar assunto da arte ou matéria de pesquisa, ou fornecer ferramentas, formatos, métodos e processos de pesquisa, até então estranhos ao próprio campo da arte. O estado pode ocorrer em dois tipos: no primeiro, aqui chamado de pesquisa quase artística, os modos de fazer seriam idênticos ou muito próximos aos utilizados nas outras disciplinas. Esquecem-se os procedimentos próprios da arte até a marca em que sobra muito pouco da obra, da artisticidade ou da produção artística, que se perde ou se dilui nessa conversa com a outra disciplina, quase tornando-se outra coisa, no limite com a ciência ou o outro conhecimento. No segundo tipo, denominado aqui como pesquisa poética associada a outros campos, é inventado

10 Também pode ser pelas tecnologias, as engenharias e a computação, tal como foi visto no estado específico chamado pesquisa em arte e tecnologia. 
um modo de fazer muito parecido ao do outro campo de conhecimento, como um método transfigurado e poético, em que a arte se disfarça de política, de etnografia, de história, por exemplo, reproduzindo e adaptando técnicas, formas, estratégias, dispositivos etc., que são específicos da outra área do saber. Entre o primeiro e o segundo tipo é claro que há gradações e misturas. O artista pode debruçar-se sobre um evento histórico, por exemplo, pesquisando arquivos relacionados ao fato, e de forma muito próxima da disciplina da História fazer descobertas e criar novas interpretações, de maneira tão consistente quanto um historiador faria, mas perpassadas pelo registro poético das Artes Visuais e com a potência da linguagem que lhe é inerente.

A pesquisa do artista, muitas vezes, mesmo no Brasil onde há hoje diversas universidades com programas próprios, acaba acontecendo em outros departamentos ou programas, sendo o mais comum a História da Arte, e então a Arquitetura, a Comunicação, a Filosofia, os Estudos Culturais etc. Sogabe adverte que "o contexto que vivemos é o interdisciplinar, e da visão sistêmica", partindo do princípio de que é impossível um artista-pesquisador hoje não "fazer conexões com outros campos do conhecimento". Por isso, muitos programas interdisciplinares vêm surgindo nos últimos tempos, e desse modo existem "não só artistas em todas as áreas, como profissionais de outras áreas nos programas de arte"11. Fervenza diz que essa busca do artista por outros áreas acadêmicas ocorre por uma questão prática e nem tanto por uma demanda que parte da produção artística. Ele elenca vários motivos para o artista não estar em um programa próprio para ele, como não ter o curso em uma cidade próxima, ter dificuldades em "fazer um projeto de pesquisa em arte", por não saber "teorizar a partir da própria obra" ou não ter um número consistente de obras. Fervenza também cita o problema de encontrar um orientador, seja pelo número reduzido de vagas, seja pela afinidade ${ }^{12}$.

Os temas a serem pesquisados pelos artistas podem ser os mais variados e vir de várias áreas do saber. Arte não existe sem pesquisa, reconhece Arlindo Machado (2016, p. 45-46), e esse é um dos três modos que o autor percebe sobre a pesquisa artística ${ }^{13}$. Nesse caso, o trabalho de investigação pode

11 Resposta do artista Milton Sogabe a questões colocadas por e-mail.

12 Resposta do artista Hélio Fervenza a questões colocadas por e-mail.

13 Arlindo Machado divide a pesquisa em arte em três atos: no primeiro, "não existe arte sem pesquisa"; no segundo, a "pesquisa é realizada dentro da própria arte"; e, no último, o autor discorre sobre a "materialidade da pesquisa". 
acontecer sobre alguma questão técnica ou tecnológica, seja sobre materiais que serão utilizados na arte, da pedra à linguagem de programação, seja sobre questões filosóficas ou estéticas, com a fenomenologia para a abstração, e ainda em torno do próprio tema da obra, surgido de infinitas fontes, de uma infinidade de tópicos, sendo que todo ou qualquer objeto poderá ser um motivo da produção artística. Na categorização "arte com pesquisa" proposta por Busch (2009), a ciência ou a filosofia dão recursos ou fundamentam obras de arte e movimentos artísticos. Aqui a autora apresenta dois tipos de exemplo: o primeiro seria o de conhecimentos científicos como ótica, teoria das cores ou anatomia, que vão auxiliar na criação das obras e nos estudos dos artistas sobre cor e desenho; o segundo exemplo trata de como autores e correntes teóricas, sendo estas científicas ou filosóficas, tais como a Psicanálise, a Fenomenologia e a Linguística, vão embasar os discursos de alguns movimentos como surrealismo, o minimalismo e arte conceitual. Em outra categoria proposta pela autora, chamada "Hibridização da arte com a pesquisa", o projeto de pesquisa artística opera sobre um campo fluido com a prática científica, em modo transdisciplinar. Nesse híbrido, formas artísticas consideradas no âmbito da produção de conhecimento contribuem para construções teóricas de outros campos. Nesse ponto, segundo Busch, a contribuição da Arte para o conhecimento não pode ser considerada, porém, de forma tão precisa como o é nas ciências. Para ela, a conversão da Arte em Ciências não resulta na cientificação da Arte, mas antes na criação de um espaço em que Arte e Ciências se conectam.

Uma das características da arte de agora, que acentua uma característica nascida no começo do século 20 , com as vanguardas, é a ânsia por relacionar-se fora da arte, rumando para espaços, serviços e atividades até então não associadas com o fazer artístico, em uma exploração sobre o que a arte deve ser, fazendo a leitura do mundo, não só como representação, mas também apoiada pelas ações, pelos acontecimentos, pelas experiências, participação e convivência (KWON, 2002; CANCLINI, 2012; FOSTER, 2014). O estado da pesquisa do artista associada a outros campos está circunscrito em um panorama maior de relações históricas e atuais entre Arte e Filosofia ou Arte e Ciência (DANTO, 2014; DELEUZE e GUATTARI, 1997), e tem um foco específico e papel de destaque no fenômeno recente da pesquisa artística, dentro ou fora da universidade, pesquisa que pode estar à margem, institucionalizada ou circulando em variados circuitos, incorporada no projeto poético, na obra de arte mesma. 


\section{7) Pesquisa do artista em vários circuitos}

Todos os estados apresentados aqui, como modos e frequências, são aspectos intercambiáveis, podem influir uns nos outros. Porém, no caso desse estado, nomeado aqui de forma instável como pesquisa do artista em vários circuitos, todas as outras qualidades podem acabar influindo em sua particularização, pelo fato de que a pesquisa do artista, entre a produção e o teórico-discursivo, entre a arte e os outros campos do conhecimento, não fica restrita necessariamente à universidade ou a uma única instituição somente, ela se desloca de forma independente através de circuitos variados, não se atém a uma única resposta, pode ser criada e exibida sem limitações, pode se posicionar à margem do que já está estabelecido.

Para Catarina Almeida (2015a, p. 114), o fenômeno da pesquisa artística no contexto do qual ela fala, o europeu, ainda não tem um terreno muito sólido para que se torne um campo de interesse para as atividades artísticas paralelas às intenções acadêmicas. Ela também diz que a relação entre o mundo da arte e a pesquisa artística foi um assunto menos explorado pelas várias publicações a respeito da pesquisa artística nos últimos anos, e que essa desconexão pode ser a causa do ceticismo vindo do "mundo da arte", que acaba se incomodando com as exigências que a posição da pesquisa exige, do artista tendo que se engajar em publicações e seminários, e também por causa de prazos e esforços por produtividade (ALMEIDA, 2015b, p. 140-145). A autora diz que se faz necessária uma visão sobre a pesquisa artística que tente conciliar esses dois mundos, para que se perceba os processos artísticos que influenciam as circunstâncias do nosso entendimento sobre a pesquisa artística na universidade. $E$ isso também se abre para a compreensão da arte contemporânea, sobre o interesse dos artistas pelas relações entre a arte e o conhecimento, e também os interesses recentes dos artistas pela conversa e pela participação, uma ideia de arte contemporânea que percebe na participação as categorias expandidas para a reconfiguração dos museus de arte como equipamentos políticos e pedagógicos. Além disso, a pesquisa artística não é só um fenômeno acadêmico, mas pode ser visto hoje como parte do projeto poético de muitos artistas.

Ricardo Basbaum, da Universidade Federal Fluminense (UFF), é um dos artistas e pensadores atuais que pensam a arte a partir da ideia de circuito(s), ao mesmo tempo que reflete sobre como se dão as ligações entre circuitos diversos e os impasses surgidos das diferenças entre métodos, propósitos e posicionamento, muitas vezes antagônicos e conflitantes. $\mathrm{O}$ artista nos lembra que as noções de circuito e sistema da arte foram criadas 
pelos artistas entre os anos 1960 e 1970, influenciados pelo campo da cibernética, porém o artista avança sobre essas ideias, mostrando um interesse muito específico sobre a economia desses circuitos: "O circuito de arte também está submetido a uma série de mecanismos reguladores que administram sua economia interna, o caminho de circulação da obra, dos valores, os jogos de poder, etc." (BASBAUM, 2002). Nesse sentido, o artista também relembra o papel que autores como Ronaldo Brito e Paulo Venâncio Filho tiveram na problematização sobre a construção de um circuito de produção da arte contemporânea brasileira, em um sentido crítico, diante do crescente mercado da arte. Circuito era uma das ideias principais formuladas pelo grupo que se formou em torno da revista Malasartes, no Rio de Janeiro, em nomes como Waltercio Caldas, Cildo Meireles, José Resende, Carlos Zilio, entre outros. O texto "Análise do circuito", de Ronaldo Brito (1975, p. 6), tentando mostrar que circuito e mercado de arte não são uma coisa só, mobilizava os artistas a "defender um campo de ação mais livre para os seus trabalhos" e a formular "estratégias de ação dentro do mercado e do circuito", procurando multiplicar "discursos críticos" e mover-se livre "dentro do sistema estabelecido de arte". Para isso, Brito propõe saídas, através da organização de grupos de artistas "em torno de um programa comum de ação dentro do circuito", como estabelecer uma relação maior entre a arte e a universidade, os espaços públicos, as instituições e o restante da cultura, criando interesse em um público de estudantes.

Colocando sua própria experiência no desenvolvimento da ideia de artista-pesquisador, e alertando para o número significativo de artistas trabaIhando sobre questões contemporâneas na academia, dentro do contexto brasileiro, Ricardo Basbaum (2013, p. 193-197) diz que na construção da imagem desse artista, a academia é apenas mais um lugar dentre uma multiplicidade de circuitos e redes artísticas em que ele pode deslocar-se. Uma das condições para o artista do século 21, segundo Basbaum (2008, p. 63), é "a possibilidade de deslocamento por diferentes papéis e locais do circuito de arte", sozinho ou agrupado em coletivos, desenvolvendo várias práticas, atividades e eventos de "agenciamento, curadoria e crítica" que se aliam à "elaboração discursiva e conceitual" sobre o fazer artístico, como organizar exposições, manter espaços independentes, publicar revistas e projetos editoriais, fazer "mediações discursivas de modalidade crítica, conceitual, teórica e histórica", oferecendo aulas oficinas e palestras, escrevendo textos e também, pode-se dizer, engajando-se com a pesquisa. 


\section{Considerações finais}

Depois de um período de estabelecimento, adversidades e discussões, a pesquisa do artista pode ser entendida de uma maneira mais abrangente, compreendendo a pesquisa de produção artística, a pesquisa teórica e vários níveis de entrelaçamento entre esses estados, não importando a predominância conferida para determinada pesquisa ou outra. Por isso, o movimento da arte que adentra o ambiente universitário, constituindo-se em uma disciplina e área específica na academia, é simultâneo a outros dois movimentos: 1 ) o da pesquisa artística que não se origina em programas de pós-graduação, mas no interesse dos artistas pelos processos de pesquisa ou por outros campos do conhecimento e o da pesquisa artística que extravasa a universidade para ser exibida em outros circuitos.

Além de resolver uma questão institucional, de especificar e delimitar um lugar e uma condição para o artista, que agora se vê como pesquisador dentro do sistema universitário, envolvido com o ensino e a pesquisa, a expressão pesquisa artística manifesta uma particularidade da produção artística contemporânea, no momento em que a pesquisa se torna poética da obra. $O$ artista se aproxima da pesquisa, pensa seu projeto poético orientado à pesquisa, cria obras de arte, de fato ou poeticamente, que incluem processos de pesquisa, motivados pela imagem e pelo ambiente da pesquisa e, além disso, faz com que a obra se torne reflexiva, teórica e discursiva. Dadas a abertura e a complexidade da arte contemporânea, o artista deve ser livre para colocar em relevo qualquer um dos estados da pesquisa artística sobre seu projeto poético ou sobre uma obra de pesquisa específica. A pesquisa artística assume diversos contornos e estilos, é realizada de um modo específico, dependendo da legislação e do sistema universitário de cada país, e vincula-se, caso seja poética da obra de arte, ao modo como cada artista trabalha e se propõe como pesquisador, e principalmente ao tipo de pesquisa que é trabalhado por ele.

A pesquisa artística na universidade deve vir, sobretudo, dos questionamentos dos artistas de agora, que não se prendem às instituições, podendo se mover entre galerias, museus, espaços independentes, publicações, grupos, transitando de modo espalhado por variados circuitos e cenas, incluindo aí a academia. Assim, a pesquisa artística não é algo que está apartada da arte, não está restrita apenas ao ambiente universitário ou realizada apenas por artistas-pesquisadores universitários, porque são o ambiente de pesquisa e o ambiente teórico que se tornam presentes para o artista em vários lugares e circuitos, reforçando a ideia de que há uma movimentação e um fenômeno da arte de agora sobre o conhecimento e o pensamento. 


\section{Bibliografia}

ALMEIDA, Catarina. After Artistic Research: What Follows the Establishment and the Realization of the Establishment of the Phenomenon. Tese (Doutorado em Educação Artística) - Faculdade de Belas Artes da Universidade do Porto, 2015a.

. The Problem of Artistic Research. Sisyphus - Journal of Education, v. 3, $\mathrm{n}^{\circ} 1$, Universidade de Lisboa, 2015b, p. 136-171. Disponível em: <https:// bit.ly/3kJV2WO>. Acesso em: 13 out. 2016.

ARANTES, Priscila.@Rte e Mídia: perspectivas da estética digital. São Paulo: Senac, 2005.

BAKER, Su et al. CreativeArtsPhD: Future Proofing the Creative Arts in Higher Education (Report). Melbourne: University of Melbourne, 2009. Disponível em: <https://bit.ly/3eLtBb2>. Acesso em: 15 fev. 2018.

BASBAUM, Ricardo. O papel do artista como agenciador de eventos e fomentador de produções frente à dinâmica do circuito da arte. In: $O$ visível e o invisível na arte atual. Belo Horizonte: CEIA - Centro de Experimentação e Informação de Arte, 2002, p. 96-119.

Além da pureza visual. Porto Alegre: Zouk, 2007.

Deslocamentos rítmicos: o artista como agenciador, como curador e como crítico. In: LAGNADO, Lisette; PEDROSA, Adriano; VOLZ, Jochen (orgs.). $27^{a}$ Bienal de São Paulo: Seminários. Rio de Janeiro: Cobogó, 2008, pp. 57-74.

O artista como pesquisador. In: . Manual do artista-etc. Rio de Janeiro: Beco do Azougue, 2013, pp. 193-201.

BIGGS, Michael. Editorial: The Problem of Interpretation in Research in the Visual and Performing Arts. In: Working Papers in Art \& Design, $n^{\circ} 5$, University of Hertfordshire, 2008. Disponível em: <https://bit.ly/2PRfl6z>. Acesso em: 17 out. 2017.

BORG, Erik. The Experience of Writing a Practice-based Thesis in Fine Art and Design. Tese (Doutorado em Educação) - Escola de Educação, Universidade de Leeds, 2009.

BORGDORFF, Henk. The Conflict of the Faculties: Perspectives on Artistic Research and Academia. Leiden: Leiden University Press, 2012.

BRITO, Ronaldo. Análise do circuito. Malasartes, n 1 , pp.5-6, Rio de Janeiro, set.-out. 1975.

BUSCH, Kathrin. Artistic Research and the Poetics of Knowledge. Art \& Research, v. 2, n², Glasgow School of Art, 2009. Disponível em: <https:// bit.ly/3glwvbX>. Acesso em: 2 fev. 2016. 
CAMPOS, Haroldo. Metalinguagem e outras metas: ensaios de teoria e crítica literária. São Paulo: Perspectiva, 1992.

CANCLINI, Néstor García. A sociedade sem relato: Antropologia e Estética da Iminência. São Paulo: Edusp, 2012.

CAZEAUX, Clive. Art, Research, Philosophy. Nova York: Routledge, 2017 (e-book Kindle).

COUCHOT, Edmond. A tecnologia na arte: da fotografia à realidade virtual. Porto Alegre: Ed. UFRGS, 2003.

DANTO, Arthur. O descredenciamento filosófico da arte. São Paulo: Autêntica, 2014.

DAVIS, Douglas. Art and The Future: A History/ Prophecy of The Collaboration Between Science, Technology and Art. Londres: Thames and Hudson, 1973.

DELEUZE, Gilles; GUATTARI, Félix. O que é a filosofia? São Paulo: Editora 34, 1997.

DOMINGUES, Diana (org.). A arte no século XXI: a humanização das tecnologias. São Paulo: Unesp, 1997.

DROMSFIELD, Jonathan Lahey. Writing as Practice: Notes on Materiality of Theory for Practice-Based PhDs. In: ELKINS, James (ed.) Artists with PhDs: On the New Doctoral Degree in Studio Art. 2. ed. Washington DC: New Academia Publishing, 2014, pp. 325-338.

ELKINS, James (ed.) Artists with PhDs: On the New Doctoral Degree in Studio Art. Washington DC: New Academia Publishing, 2014.

FOSTER, Hal. O retorno do real. São Paulo: Cosac Naify, 2014.

HOLERT, Tom. Art in the Knowledge-based Polis. e-flux journal, n³, fev. 2009. Disponível em: <https://bit.ly/2FpxuX3>. Acesso em: 9 jan. 2016.

KWON, Miwon. One Place After Another: Site-specific Art and Locational Identity. Cambridge: MIT Press, 2002.

MACHADO, Arlindo. A pesquisa em arte em três atos. In: PRADO, Gilbertto; TAVARES, Monica; Tavares; ARANTES, Priscila (orgs.). Diálogos transdisciplinares: arte e pesquisa. São Paulo: ECA-USP, 2016, pp. 44-52.

MANOVICH, Lev. The Language of New Media. Cambridge: The Mit Press/ Leonardo Books, 2001.

OITICICA, Hélio. Depoimento concedido a Ivan Cardoso para o filme H.O. [jan. 1979]. In: FILHO, Cesar Oiticica e VIEIRA, Ingrid (orgs.). Hélio Oiticica. Rio de Janeiro: Beco do Azougue, 2009, pp. 226-243. (Encontros). 
PECCININI, Daisy. Crônica dos primeiros tempos da ANPAP (1985 - 1991 2017). 25 set. 2017. Disponível em: <https://bit.ly/3hgPcK5>. Acesso em: 5 out. 2017.

PLAZA, Julio. Arte/ciência: uma consciência. ARS, v. 1, $\mathrm{n}^{\circ} 1$, São Paulo, 2003, pp. 36-47. Disponível em: <https://bit.ly/3fXsvJB>. Acesso em: 27 set. 2017.

REY, Sandra. Da prática à teoria: três instâncias metodológicas sobre a pesquisa em artes visuais. Porto Arte, n¹3, v. 7, pp. 81-95, Porto Alegre, 1996.

SLAGER, Henk. The Pleasure of Research. Berlim: Hatje Cantz, 2015.

SOGABE, Milton. Arte e Pesquisa na Academia. In: RIBEIRO, Walmeri e ROCHA, Thereza (eds.). Das artes e seus territórios sensíveis. São Paulo: Intermeios, 2014, pp. 21-32.

ZANINI, Walter. Elementos sobre a pesquisa em Artes Plásticas no Brasil e ANPAP (1987-1989). In: RAMALHO E OLIVEIRA, Sandra; MAKOWIECKY, Sandra (orgs.). Uma história da Associação Nacional de Pesquisadores em Artes Plásticas. Florianópolis: UDESC, 2008, pp. 33-38.

ZAMBONI, Silvio. A pesquisa em arte: um paralelo entre arte e ciência. Campinas, SP: Editora Autores Associados, 1998.

Situação atual da pesquisa em/sobre arte. In: MOREIRA, Maria Carla Guarinello de Araújo (org.). Arte em pesquisa. Londrina: EDUEL, 2005, pp. 189-204. 